\title{
PERLINDUNGAN HUKUM ATAS KARYA CIPTA TERHADAP TINDAKAN FANFIKSASI STUDI PADA NOVEL THE TWILIGHT SAGA "BREAKING DAWN" DAN WEB NOVEL RENESMEE'S NORMAL LIFE
}

\author{
Pritha Arintha Natasaputri \\ Magister Hukum Universitas Semarang
}

\begin{abstract}
ABSTRAK
Penelitian ini bertujuan untuk mengetahui bentuk perlindungan hukum yang diberikan Undang-Undang kepada pencipta atau pemegang hak cipta karya asli terhadap Terhadap Tindakan Fanfiksasi Studi Pada Novel The Twilight Saga "Breaking Dawn" dan Web Novel Renesmee's Normal Life Suatu Kajian Undang - Undang Nomor 28 Tahun 2014 Tentang Hak Cipta. Penelitian ini menggunakan pendekatan yuridis normative. Adapun temuan yang diperoleh dari penelitian ini, yaitu: 1) Legalitas karya fanfiction bersifat tentative, tergantung sejauh mana karya fanfiction tersebut tidak melanggar hak ekonomi dan hak moral pencipta karya asli. Untuk mengetahui apakah suatu fanfiction melanggar atau tidak, harus dikualifikasidengan penilaian kualitatif yang ditetapkan dalam Undang-Undang.Fanfiction sebagai karya derivative yang dibuat tanpa seizin pencipta karya asli telah diakomodir keberadaannya dalam Undang-Undang melalui mekanisme pembatasan hak cipta (fair use doctrine) dengan menetapkan beberapa kualifikasi diantaranya; tujuan penggunaan untuk kepentingan pendidikan dan pertunjukan yang tidak komersil, serta harus memperhatikan hak paternitas dan hak integritas pencipta. Penilaian terhadap karya fanfiction harus dilihat secara kasus perkasus karena tujuan penggunaan dan konten setiap karya fanfiction berbeda-beda. 2) Bentuk perlindungan hukum atas pencipta karya asli terhadap modifikasi karya asli, yaitu; Pertama, perlindungan hukum secara preventif mempunyai tujuan untuk mencegah terjadinya sengketa atau permasalahan; dan Kedua, perlindungan hukum secara represif mempunyai tujuan untuk menyelesaikan sengketa.
\end{abstract}

Kata kunci : Fanfiksi; hak cipta; perlindungan 


\title{
LEGAL PROTECTION OF COPYRIGHT ON FANFIKSATION STUDY ACTIONS IN THE TWILIGHT SAGA NOVEL "BREAKING DAWN" AND WEB NOVEL RENESMEE'S NORMAL LIFE
}

\author{
Pritha Arintha Natasaputri \\ Master of Law, University of Semarang
}

\begin{abstract}
This study aims to determine the form of legal protection that is given the Act to the creator or the copyright holder of the original work against the action of Fanfiksasi Studi Pada Novel The Twilight Saga "Breaking Dawn" dan Web Novel Renesmee's Normal Life Suatu Kajian Undang - Undang Nomor 28 Tahun 2014 Tentang Hak Cipta

This study uses a normative juridical approach. The findings obtained from this study are: 1) Legality of fanfiction work is tentative, depending on the extent to which fanfiction works do not violate the economic rights and moral rights of the original creator. To find out whether a fanfiction violates it or not, it must be qualified with a qualitative assessment stipulated in the Law. Fanfiction as a derivative work made without permission from the creator of the original work has been accommodated in the Act through the copyright use mechanism (fair use doctrine) by stipulating some qualifications include; the purpose of use for educational and performance purposes that are not commercial, and must take into account the paternity rights and integrity rights of the creator. Assessment of fanfiction works must be seen in case of case study because the purpose of the use and content of each fanfiction work is different. 2) Form of legal protection for the creator of the original work against the modification of the original work, namely; First, preventive legal protection has the aim of preventing disputes or problems; and Second, repressive legal protection has the aim of resolving disputes.
\end{abstract}

Keywords : Fanfiction; copyright; legal protection 


\section{A.PENDAHULUAN}

Secara substansif, Hak Atas Kekayaan Intelektual (HAKI) dapat dideskripsikan sebagai hak atas kekayaan yang timbul atau lahir karena kemampuan intelektual manusia. ${ }^{1}$ HAKI ini berasal dari kreativitas intelektual manusia. Bentuknya nyata, tidak hanya sekadar ide, gagasan atau pun konsep. Ada kreativitas yang diwujudkan secara nyata atau fakta. Ia melindungi segenap ekspresi dari ide, gagasan serta konsep.

Berkenaan dengan hal di atas, maka ada satu pengertian hak kekayaan intelektual yang dirumuskan dalam kalimat : "The term intellectual property refers broadly to the creations of the human mind. Intellectual property right protect the interest of creators by giving them property rights over their creations."

Fenomena tersebut melahirkan banyak fanfic yang beredar di dunia maya. Baik di blog atau sosial media lainnya, maupun website menulis bernama www.fanfiction.net. Renesmee's Normal Life adalah salah satu web novel yang lahir dari website menulis bernama www.fanfiction.net. Biasnya batas-batas mengenai keberadaan sebuah fanfic atau fiksi penggemar serta sejauh mana keserupaan ide dasar dapat dieksplorasi sehingga karya tersebut merupakan satu kesatuan tersendiri dan bukannya plagiasi atau pelanggaran hak cipta membuat Penulis tertarik mengambil judul penelitian Perlindungan Hukum Atas Karya Cipta Novel Terhadap Tindakan Fanfiksasi Studi Pada Novel The Twilight Saga “Breaking Dawn” dan Web Novel Renesmee’s Normal Life Suatu Kajian Undang - Undang Nomor 28 Tahun 2014 Tentang Hak Cipta dimana peraturan mengenai hal tersebut tidak diatur secara terperinci oleh Undang-Undang, terutama UUHC.

\section{B. PERMASALAHAN}

Rumusan permasalahan yang akan dibahas adalah :

${ }^{1}$ Suyud Margono, Hak Kekayaan Intelektual Komentar atas Undang-Undang Rahasia Dagang, Desain Industri, Desain Tata Letak Sirkuit Terpadu, (Jakarta : CV. Novindo Pustaka Mandiri, 2001), hlm. 9

${ }^{2}$ Muhammad Djumhana dan R. Djubaedillah, Hak Milik Intelektual (Sejarah, Teori, dan Praktiknya di Indonesia), (Bandung : PT Citra Aditya Bakti, 2014), hlm. 16 
1. Bagaimana perlindungan hukum atas karya cipta terhadap tindakan fanfiksasi studi pada novel The Twilight Saga "Breaking Dawn dan web novel Resnesmee's Normal Life?

2. Bagaimana kendala dan solusi atas perlindungan hukum atas karya cipta novel terhadap tindaka fanfiksasi studi pada novel The Twilight Saga "Breaking Dawn dan web novel Resnesmee's Normal Life suatu kajian Undang-Undang Nomor 28 Tahun 2014 ?

\section{TINJAUAN PUSTAKA}

Intellectual Property Right (IPR) diatur pada Undang-Undang Nomor 4 Tahun 1994 tentang pengesahan WTO (Agreement Establishing The World Trade Organization). Istilah tersebut berasal dari kepustakaan hukum Anglo Saxon. ${ }^{3}$ Dalam Bahasa Belanda, IPR dikenal pula dengan sebutan Intellectuele Eigendomrecht sedang pada Bahasa Indonesia diterjemahkan sebagai Hak Milik Intelektual (HMI). Hal tersebut bersumber pada konsepsi Hak Milik Kebendaan yang tercantum pada KUHPerdata pada pasal 499, 501, 502, 503 dan 504. Penggunaan sebutan HMI adalah sesuatu hal yang logis untuk memilih langkah yang konsisten dalam kerangka berpikir yuridis normatif.

HKI merupakan hak yang berasal dari hasil kreatif suatu kemampuan daya pikir manusia yang diekspresikan kepada masyarakat umum dalam berbagai bentuknya, yang memiliki manfaat serta berguna dalam menunjang kehidupan menusia juga memiliki nilai ekonomis. Bentuk nyata dari kemampuan karya intelektual tersebut contohnya dalam bidang teknologi, ilmu pengetahuan maupun seni dan sastra. Sebagai suatu hak milik yang timbul dari karya, karsa, cipta manusia atau dapat pula disebut sebagai hak kekayaan intelektualitas manusia. Hasil kreasi tersebut, dalam masyarakat beradab, diakui bahwa yang menciptakan boleh menguasai untuk tujuan yang menguntungkannya. Kreasi sebagai milik

${ }^{3}$ Rachmadi Usman, Hukum Hak dan Kekayaan Intelektual, Perlindungan dan Dimensi Hukumnya di Indonesia, (Bandung : Alumni, 2003), hlm. 1 
e-ISSN : 2621-4105

berdasarkan hak milik dalam arti seluas-luasnya yang meliputi hak milik tidak berwujud. $^{4}$

\section{METODE PENELITIAN}

Metode penelitian yang digunakan adalah yuridis normatif. Pendekatan yang dilakukan dengan penelitian kepustakaan terhadap data sekunder.

Spesifikasi penelitian dalah deskritif analisis, yakni akan dilakukan penelitian terhadap Novel The Twilight Saga "Breaking Dawn” dan Web Novel Renesmee's Normal Life, dan data pendukung lainnya, yang nantinya membatu membentuk kesimpulan dari hasil penenlitian.

Data sekunder yang diperoleh dari studi kepustakaan mencangkup :

1. Bahan Hukum Primer : Peraturan perundang-undangan, khususnya Kitab Undang-Undang Hukum Perdata, serta Peraturan perundang-undangan lainnya mengenai Hak Cipta.

2. Bahan Hukum Sekunder : terdiri dari literature bacaan dalam bentuk buku mengenai hak cipta, serta literature bacaan lainnya, seperti jurnal, artikel, datadata terkait, dan lain-lain.

Metode analisis yang digunakan adalah kualitatif. Dalam penenlitian ini tidak menggunakan angka-angka untuk menganalisis data yang diperoleh.

\section{E.PEMBAHASAN}

\section{Perlindungan Hukum Atas Karya Cipta Novel terhadap Tindakan Fanfiksasi} Studi Pada Novel The Twilight Saga "Breaking Dawn" dan web novel Renesmee's Normal Life

Perlindungan hukum atas karya cipta novel terhadap fanfiksasi merupakan kewenangan daripada pemerintah sebagai penyelenggara pemerintahan yang dapat dilihat dari penafsiran Undang-Undang Nomor 28 Tahun 2014 tentang Hak Cipta, namun hal tersebut belum diatur secara jelas dalam Undang-Undang tersebut.

${ }^{4}$ Roscou Pound, Pengantar Filsafat Hukum (terjemahan Mohammad Radjab), Cetakan Ketiga, (Jakarta : Bhatara Aksara Karya, 1982), hlm. 21 
Perlindungan hukum terhadap hak cipta pada dasarnya dimaksudkan sebagai upaya untuk mewujudkan iklim yang lebih baik bagi tumbuh dan berkembangnya gairah mencipta di bidang ilmu pengetahuan, seni dan sastra. Menyadari akan hal tersebut, pemerintah Indonesia secara terus menerus berusaha untuk memperbaharui peraturan perundang-undangan di bidang hak cipta untuk menyesuaikan diri dengan perkembangan yang ada, baik perkembangan di bidang ekonomi maupun di bidang teknologi.

\section{Kendala dan Solusi atas Perlindungan Hukum atas karya cipta terhadap} tindakan fanfiksasi studi pada novel The Twilight Saga "Breaking Dawn" dan web novel Renesmee's Normal Life

Kendala utama terhadap fanfiksasi belum adanya kepastian hokum. Sehingga peran pemerintah adalah merevisi Undang-Undang Nomor 28 Tahun 2014 tentang Hak Cipta sehingga tidak terjadi vacuum of law (kekosongongan hukum).

Fanfiksi adalah sebuah pop culture atau kultur populer yang dipengaruhi oleh komunitas fandom yang memproduksi serta mengkonsumsi cerita turunan atau tambahan pada media terkait dengan sesuatu yang menarik minat anggota komunitas tersebut. Penggunaan cerita yang telah ada, sebuah karya kreatif dan ide-ide sebagai basis karya yang baru telah dipraktekkan berabad-abad lalu oleh penulis, pendongeng dan semacamnya.

Peristiwa fanfiksi novel The Twilight Saga "Breaking Dawn” terhadap web novel Renesmee's Normal Life ini adalah salah satu bukti adanya plagiasi yang berlindung dibalik topeng fanfiksi. Hanya saja, tidak ada peristiwa hukum yang terjadi mengingat Stephenie Meyer sebagai penulis asli serta Gramedia Pustaka Utama sebagai penerbit novel The Twilight Saga "Breaking Dawn" tidak mengajukan aduan kepada pihak yang berwenang terkait adanya plagiasi. Pada Pasal 120 UUHC jelas tertera untuk perkara pelanggaran Hak Cipta memakai delik aduan. Selama tidak ada yang mengadu maka tidak akan terjadi peristiwa hukum. 
Fanfiksi sebagai budaya baru dalam dunia literasi memang patut diapresiasi. Akan tetapi sebaiknya harus ditindaklanjuti dengan peraturan-peraturan yang memadai untuk melindungi kepentingan pihak-pihak yang terkait, yaitu penulis asli, penerbit serta penulis fanfiksi itu sendiri. Sementara ini perlindungan hukum masih bersumber pada UUHC, tepatnya pasal 112, 113, 116-118. Menurut penulis, hukum dibuat untuk mengayomi masyarakat dengan keadaan-keadaan serta perkembangan zaman. Akan tetapi perkembangan zaman akan selalu mendahului adanya hukum.

\section{F. PENUTUP}

Peristiwa fanfiksasi novel The Twilight Saga "Breaking Dawn” terhadap web novel Renesmee's Normal Life ini adalah salah satu bukti adanya plagiasi yang berlindung dibalik topeng fanfiksi. Hanya saja, tidak ada peristiwa hukum yang terjadi mengingat Stephenie Meyer sebagai penulis asli serta Gramedia Pustaka Utama sebagai penerbit novel The Twilight Saga "Breaking Dawn" tidak mengajukan aduan kepada pihak yang berwenang terkait adanya plagiasi. Pada Pasal 120 UUHC jelas tertera untuk perkara pelanggaran Hak Cipta memakai delik aduan. Selama tidak ada yang mengadu maka tidak akan terjadi peristiwa hukum. Fanfiksi sebagai budaya baru dalam dunia literasi memang patut diapresiasi. Akan tetapi sebaiknya harus diberikan kepastian hukum melalui peraturan-peraturan yang memadai untuk melindungi kepentingan pihak-pihak yang terkait, yaitu penulis asli, penerbit serta penulis fanfiksi itu sendiri. Sementara ini perlindungan hukum masih bersumber pada UUHC, tepatnya pasal 112, 113, 116-118. Menurut penulis, hukum dibuat untuk mengayomi masyarakat dengan keadaan-keadaan serta perkembangan zaman. Akan tetapi perkembangan zaman akan selalu mendahului adanya hukum. 
e-ISSN : 2621-4105

\section{DAFTAR PUSTAKA}

\section{Buku}

Suyud Margono, Hak Kekayaan Intelektual Komentar atas Undang-Undang Rahasia

Dagang, Desain Industri, Desain Tata Letak Sirkuit Terpadu, (Jakarta : CV. Novindo Pustaka Mandiri, 2001)

Muhammad Djumhana dan R. Djubaedillah, Hak Milik Intelektual (Sejarah, Teori, dan Praktiknya di Indonesia), (Bandung : PT Citra Aditya Bakti, 2014)

Rachmadi Usman, Hukum Hak dan Kekayaan Intelektual, Perlindungan dan Dimensi Hukumnya di Indonesia, (Bandung : Alumni, 2003)

Roscou Pound, Pengantar Filsafat Hukum (terjemahan Mohammad Radjab), Cetakan

Ketiga, (Jakarta : Bhatara Aksara Karya, 1982) 